\title{
Geoengineering and Public Trust Doctrine
}

\author{
Andrew Lockley, Gideon Futerman and D'Maris Coffman*
}

Geoengineering (the deliberate modification of the climate system), has been discussed as a technique to control Anthropogenic Global Warming (AGW). ${ }^{1}$ Public Trust Doctrine (PTD) is used to hold assets that are not in private ownership in a form of collective ownership for public benefit; it is familiarly applied to the shoreline between tides. Several variants of PTD exist, yet all variants serve to limit private ownership. The version arising from Anglo-American common law creates duties and responsibilities on the sovereign to maintain and preserve assets in public trust. We consider various types of geoengineering to protect example assets currently under PTD, finding a compelling case for action in a variety of contexts. This introduces a paradoxical situation, where it may theoretically be easier to compel states to undertake geoengineering to protect a beach, than to protect the whole planet. We note that, whilst PTD obligations are atomised in nature, the inherent commonality of the threat potentially serves to reduce this fragmentation, and to encourage common action amongst states. However, we note the failure of recent legal proceedings, which exposes practical limitations on the ability of PTD to compel climate action generally - and thus its applicability to geoengineering.

\section{Introduction}

The difficulties in swiftly decarbonising the global economy have resulted in a renewed consideration of geoengineering as an alternative and supplement to mitigation and adaptation. In its modern usage, geoengineering is understood to mean the deliberate modification of the climate system. Geoengineering has two key strands:

- CDR/GGR: Carbon Dioxide Removal relates to removal of atmospheric $\mathrm{CO}_{2}$ - directly, or indirectly (e.g. by treating seawater). The set of technologies known as Greenhouse Gas Removal (GGR) ${ }^{2}$ additionally includes removal of secondary Greenhouse Gases (GHGs), such as methane, and halocarbons. Cost is the major impediment to CDR deployment ( $50 \mathrm{EUR} /$ ton $\mathrm{CO}_{2}$ is suggested by IEAGHG ${ }^{3}$ ).

DOI: $10.21552 / \mathrm{ccl} / 2020 / 2 / 4$

* Andrew Lockley, CPM, UCL Bartlett. Gideon Futerman, Immanuel College. D'Maris Coffman, CPM, UCL Bartlett. For Corresspondence: <andrew.lockley@gmail.com>

1 National Academy of Sciences, Climate Intervention: Reflecting Sunlight to Cool Earth, (National Academies Press: Washington, DC 20001, 2015); J G Shepherd et al, 'Geoengineering the Climate: Science, Governance and Uncertainty' (Royal Society: London 2009).

2 G Lomax et al, 'Reframing the Policy Approach to Greenhouse Gas Removal Technologies' (2015) Energy Policy 78, 125-136.
- SRM: Solar Radiation Management is a suite of techniques based on the principle of modifying the Earth's radiation balance through partial reflection of sunlight. Advocates of SRM suggest various schemes: marine cloud brightening (MCB); cirrus cloud thinning (CCT); and stratospheric aerosol injection (SAI). The resulting SRM-modified climate would either be drier, or warmer, than the pre-industrial world. Furthermore, warming is not the only severe risk from $\mathrm{CO}_{2}$ emissions (e.g. ocean acidification is also a major threat). Moreover, there are major risks and controversies which make policymakers reluctant to deploy SRM at present. ${ }^{4}$

When the term geoengineering is used without clarification in this article, it should be taken to refer to

3 International Energy Agency Greenhouse Gas R\&D Programme (IEAGHG), 'Potential for Biomass $\mathrm{CO}_{2}$ Capture and Storage' (eenews, 6 July 2011) <https://www.eenews.net/assets/2011/08/ 04/document_cw_01.pdf> accessed 28 June 2020.

4 Other authors have provided helpful summaries of relevant arguments and literature, in the field of SRM governance. See only J L Reynolds, 'Solar Geoengineering to Reduce Climate Change: A Review of Governance Proposals' (2019) 475 Proceedings of the Royal Society A: Mathematical, Physical and Engineering Sciences 2229, 20190255; J A Flegal et al, 'Solar Geoengineering: Scientific, Legal, Ethical, and Economic Frameworks' (2019) 44 Annual Review of Environment and Resources 1. 
both SRM and CDR. With the exception of afforestation initiatives and suchlike, to date no large-scale geoengineering has been deployed. Nevertheless, experts concur that neither CDR nor SRM are likely to pose insurmountable engineering challenges. ${ }^{5}$ However, some forms, e.g. space mirrors, are currently prohibitively expensive. ${ }^{6}$

Despite the absence of historical deployments, geoengineering has a prominent place in current global warming discourses and debates. CDR, in particular, is becoming embedded in major international agreements as the third leg of the mitigation, adaptation, geoengineering tri-partite response to climate change. The recent Paris treaty projects large-scale CDR deployment in the latter half of the $21^{\text {st }}$ century. ${ }^{7}$ Conversely, SRM is not part of the current policy mix. This may well change, as SRM techniques can be rapidly and inexpensively deployed. SRM is also cost effective, ${ }^{8}$ with estimates of operational costs as little as $\$ 1 \mathrm{bn} / \mathrm{yr}$ to deliver a $1 \mathrm{~W}$ m-2 solar flux change; with the upper bound for deployment costs being, according to McClellan, a little more than $\$ 2$ billion USD per year ${ }^{9}$. Another study has the figure for halving the temperature change at between $\$ 2$ billion and $\$ 2.5$ billion USD ${ }^{10}$. These estimates could potentially be reduced significantly by delivery via drone aircraft, and similar automation elsewhere in the supply chain; drone technologies are evolving quickly, although the authors are not aware of calculations regarding this at present. Either way, direct costs of SRM are negligible as a percentage of global GDP.

5 Royal Society, 'Geoengineering the Climate: Science, Governance and Uncertainty' (Royal Society, 2020) <https:// royalsociety.org/ /media/Royal_Society_Content/policy/ publications/2009/8693.pdf> accessed 10 February 2020.

$6 \mathrm{~K}$ Schrogl and L Summerer, 'Climate Engineering and Space' (2016) Acta Astronautica 129, 121-129.

7 S Lewis 'The Dirty Secret of the Paris Climate Deal' (Foreign Policy, 17 December 2015) <https://foreignpolicy.com/2015/12/ 17/the-dirty-secret-of-the-paris-climate-deal-carbon-capture -negative-emissions-global-warming/> accessed 20 May 2016.

8 J McClellan, D Keith and J Apt, 'Cost Analysis of Stratospheric Albedo Modification Delivery Systems' (2012) 7 Environmental Research Letters 3, 034019.

9 ibid

10 W Smith and G Wagner, 'Stratospheric Aerosol Injection Tactics and Costs in the First 15 Years of Deployment' (2018) 13 Environmental Research Letters 12, 124001.

11 A Lockley, 'Licence to Chill' (2016) 18 Environmental Law Review 1, 25-40.

12 A Lockley, 'State Procurement of Geoengineering, Ethics Policy and Environment' (forthcoming).
Future deployment of geoengineering may be made by commercial firms, ${ }^{11}$ or by states and their proxies. Likewise, two models for the possible future commercial commissioning of geoengineering exist - depending on whether states, or private citizens and firms, are the ultimate customers. ${ }^{12}$

An important risk of SRM is the threat of 'termination shock'. This would occur if the deployment were to be interrupted, ${ }^{13}$ due to the short lifetime of SRM aerosols. Abrupt SRM termination is dangerous, as the rate of increase of global temperature is a major risk factor for the biosphere. ${ }^{14}$ Accordingly, regulatory processes and procedures for SRM must ensure that any exit from a programme is orderly and thus does not expose the climate to avoidable risk of termination shock. One viable method for achieving this is a smooth transition to CDR. In this case, SRM simply acts as a bridge, constraining temporary temperature rises, whilst CDR deployment is awaited.

SRM is not a homogenous commodity and one kilo of injection is not automatically equivalent to another. Various classes of SRM are fundamentally different: SAI is more long-lasting; MCB is more temporarily and spatially controllable. ${ }^{15}$. There also exists the less well studied cirrus cloud thinning. ${ }^{16} \mathrm{SAI}$ is much more persistent than is MCB (approximately two years vs. days). SAI deployments are global in effect, tending to be spread rapidly on zonal winds, ${ }^{17}$ and spread more slowly poleward by the Brewer-Dobson circulation. ${ }^{18}$ SAI broadly remains within the Northern or Southern hemisphere, according to the locus of injection. ${ }^{19}$

13 K McCusker, et al, 'Rapid and Extensive Warming Following Cessation of Solar Radiation Management' (2014) 9 Environmental Research Letters 2, 024005.

14 D MacMartin et al, 'Solar Geoengineering to Limit the Rate of Temperature Change' (2014) 372 Philosophical Transactions of the Royal Society A: Mathematical, Physical and Engineering Sciences 2031), 20140134-20140134.

15 J Latham, 'Amelioration of Global Warming by Controlled Enhancement of the Albedo and Longevity of Low-level Maritime Clouds' (2002) Atmos Sci Lett 3, 52-58.

16 D L Mitchell and W Finnegan, 'Modification of Cirrus Clouds to Reduce Global Warming' (2009) 4 Environmental Research Letters 4, 045102.

17 C Brühl et al, 'Stratospheric Sulfur and its Implications for Radiative Forcing Simulated by the Chemistry Climate Model EMAC' (2015) 120 Journal of Geophysical Research: Atmospheres 5, 2103-2118.

18 D Keith, 'Photophoretic Levitation of Engineered Aerosols for Geoengineering' (2010) 107 Proceedings of the National Academy of Sciences 38, 16428-16431.

19 J Haywood et al, Asymmetric Forcing from Stratospheric Aerosols Impacts Sahelian Rainfall' (2013) 3 Nature Climate Change 7 660-665. 
Hemispheric imbalances in deployment cause significant disruption to the Inter-Tropical Convergence Zone - and therefore major disruption to the climate of the wider equatorial region (such as the Sahel region). MCB and CCT are more locally specific. However, teleconnections in the climate mean that these techniques do not have a cleanly isolated effect. ${ }^{20}$ Further, SAI and MCB are expected to have differing effects on precipitation. The precise nature of this difference will vary according to the detail of the injection regime. ${ }^{21}$

Existing authors primarily discuss geoengineering in the context of two potential deployment scenarios: state provision/ regulation; ${ }^{22}$ or the rogue 'Greenfinger' philanthropist. ${ }^{23}$ Criticism of this limited scope, including consideration of alternative funding models, can be found in existing literature. ${ }^{24}$

A public good is non-excludable and non-rivalrous. Its consumption cannot be prevented, and consumption does not reduce availability. Such goods, e.g. street lighting, are usually provided by the state. Geoengineering is widely regarded as a public good, ${ }^{25}$ although some differ from this consensus view. $^{26}$

\section{Public Trust Doctrine}

A trust is a legal instrument that allows the retention of an asset in a legal vehicle controlled by a party oth-

20 S Hill and Y Ming (2012). 'Nonlinear Climate Response to Regional Brightening of Tropical Marine Stratocumulus' (2012) 39 Geophys Res Lett 15.

21 A Jones et al, 'A Comparison of the Climate Impacts of Geoengineering by Stratospheric SO2 Injection and by Brightening of Marine Stratocumulus Cloud' (2010) 12 Atmosph Sci Lett 2, 176-183.

22 K L Ricke et al, 'Strategic Incentives For Climate Geoengineering Coalitions To Exclude Broad Participation' (2013) Environ Res Lett 8.1, 014021

23 D G Victor, 'On The Regulation Of Geoengineering' (2008) 24 Oxford Review of Economic Policy 2, 322-336.

24 A Lockley, 'Geoengineering: A War On Climate Change?' (2016) 26 Journal of Evolution and Technology 1.

25 D Morrow, 'Why Geoengineering Is A Public Good, Even If It Is Bad' (2014) 123 Climatic Change 2, 95-100.

26 S Gardiner, 'Why Geoengineering Is Not A 'Global Public Good', And Why It Is Ethically Misleading To Frame It As One' (2013) 121 Climatic Change 3, 513-525.

27 See 'Trust' in Black's Law Dictionary (St Paul, Minnesota: West Publishing, Inc. 1951), 1680-1.

28 C J Wright, God's People in God's Land: Family, Land, and Property in the Old Testament (Wm. B. Eerdmans Publishing, 1990). er than that which is the beneficial owner. ${ }^{27}$ Although they may have more ancient origins, the first appearances of land trusts can be found in biblical accounts. $^{28}$

Public Trust Doctrine (PTD) concerns a system of common ownership, whereby commons are held in trust for public benefit.

'The principle that certain natural and cultural resources are preserved for public use, and that the government owns and must protect and maintain these resources for the public's use. For example, under this doctrine, the government holds title to all submerged land under navigable waters. Thus, any use or sale of such land must be in the public interest. ${ }^{29}$

PTD has emerged as a feature of modern environmental law, ${ }^{30}$ with some claiming it to have enormous potential in terms of environmental litigation. ${ }^{31}$ As such, the concept of public trust doctrine has been invoked in a wide range of recent legal cases, in a number of jurisdictions - even in the absence of plaintiffs. ${ }^{32}$ Especially notable are a clutch of cases involving child plaintiffs: in Pakistan, ${ }^{33}$ a range of US states, ${ }^{34}$ and a number of other countries around the world ${ }^{35}$, although their scope and applicability may be limited. PTD is found in the case law and legal regimes of many, although not all, countries. PTD in its modern sense is seen to originate as part of English Common Law. ${ }^{36}$ PTD is recognised as a valid legal doctrine in the case law of 41 US states ${ }^{37}$ and by the US Supreme Court. ${ }^{38}$ PTD is found in the case

29 Public Trust Doctrine. LII / Legal Information Institute. 2016 Available at: <https://www.law.cornell.edu/wex/public_trust _doctrine> accessed 22 May 2016.

30 P Kameri-Mbote, 'Use of the Public Trust Doctrine in Environmental Law' (2007) 3 Law Env't \& Dev J, 196.

31 J Sax, 'The Public Trust Doctrine in Natural Resource Law: Effective Judicial Intervention' (1970) 68 Michigan Law Review 3, 471.

32 Environmental Law Institute, 'Constitutional Environmental Law: Giving Force to Fundamental Principles in Africa' (2007) 1585761044, 9781585761043

33 Our Children's Trust, 'Pakistan'<http://ourchildrenstrust.org/legal/international/Pakistan> accessed 22 May 2016.

34 Our Children's Trust, 'State Lawsuits' <http://ourchildrenstrust.org/ US/LawsuitStates> accessed 22 May 2016.

35 Our Children's Trust, 'International Legal Actions' <http:// ourchildrenstrust.org/legal/international> accessed 22 May 2016.

36 E.g. Juliana the Washerwoman 1299, Hampshire Record Office, Winchester City Archives, Borough Court Roll.

37 The Wildlife Society, 'The Public Trust Doctrine' <https://wildlife .org/wp-content/uploads/2014/05/ptd_10-1.pdf> accessed 7 February 2020.

38 Illinois Central R. Co. v. Illinois, 146 U.S. 387 (1892). 
law of India, ${ }^{39}$ as well as located in the constitution, according to the Supreme Court. ${ }^{40}$ It is also found in the case law of the Philippines, ${ }^{41}$ and Canada. ${ }^{42}$ Moreover, PTD is anchored in Article 237 of the Ugandan constitution. ${ }^{43}$ It must also be noted that in many cases, PTD has been based on the right to $\operatorname{life}^{44}$ and the right to a safe environment, ${ }^{45}$ and thus the authors argue that there is potentially scope for its use in other countries that have the right to life and to a safe environment enshrined in their constitution. Notable for this article, PTD is not particularly widespread in small island states, although the right to life is. ${ }^{46,47}$ The right to life is part of international law in Article 3 of the Universal Declaration of Human Rights ${ }^{48}$ and the International Covenant on Civil and Political Rights, ${ }^{49}$ although there are no cases that link PTD to international law through these as far as the authors are aware. It is important to recognise before proceeding the importance of the American conception of PTD, as this strongly influenced many other countries' conceptions of PTD, such as South Africa and India. ${ }^{50}$

PTD has been used in several recent cases brought against governments based on their failure to take sufficient climate action ${ }^{51}$, and Komor v. USA has even used PTD implicitly to argue for action on geoengineering. ${ }^{52}$ As PTD is becoming more commonly invoked to sue for climate action, it is becoming increasingly relevant to discuss. It is particularly important to speak of the Juliana $v$. USA ${ }^{53}$ case in this context. Here, despite the court recognising the ne-

39 M.C.Mehta v. Kamal Nath and Others (1997)1 SCC 388.

40 M I Builders Pvt Ltd v. Radhey Shyam Sahu \& Ors (1999) INSC 228.

41 MMDA v Concerned residents of Manila Bay GR Nos 171947-48.

42 City of Vancouver v. Burchill [1932] S C R 620 (Can).

43 Constitution of the Republic of Uganda <http://www.statehouse go.ug/sites/default/files/attachments/Constitution_1995.pdf > accessed 12 February 2020

44 E.g. in India in M I Builders Private Ltd v Radhey Shyam Sahu, (1999) 6 S C C 466.

45 E.g. Art 14 of the 2008 Constitution of Ecuador.

46 E.g. Art 21 of the Maldives Constitution.

47 E.g. S 8 of the 2013 Constitution of Fiji.

48 UN General Assembly, Universal Declaration of Human Rights, 10 December 1948, 217 A (III) < https://www.refworld.org/docid/ 3ae6b3712c.html> accessed 13 February 2020.

49 UN General Assembly, International Covenant on Civil and Political Rights, 16 December 1966, United Nations, Treaty cessity for urgent action on climate change, the majority ruled that an Article III court did not have the power to mandate such action, rather it could only come from the political branches. ${ }^{54}$ If this is upheld in higher courts, it may indicate that PTD is not strong enough to compel the US Federal Government to carry out any climate action. Considering that Komor $v$. USA is a very similar case to Juliana $v$. USA, this may mean that PTD as a mechanism to compel action on geoengineering is unlikely to work in the US Federal context. It must be noted that the minority opinion stated the court did have the power to rectify what it considered a constitutional breach, and compared the case to Brown v. Board of Education..$^{55}$ However, this was based on the idea that climate change presented a threat to the republic, rather than relying on Public Trust Doctrine. ${ }^{56}$ Elsewhere the Dutch Supreme Court has ruled they do have the power to compel the Dutch government to act on climate change. ${ }^{57}$ It is clear that the power of judicial rulings to promote climate action differs by jurisdiction. Moreover, the conception of PTD invoked in Juliana v. USA was PTD extended to the atmosphere, rather than with regards to assets that PTD is commonly applied to. However, Juliana v. USA is one of the highest profile cases using PTD in relation to climate change to be ruled on thus far, and it must be noted, the US precedent on PTD carries a lot of weight around the world, for example in an Indian context. ${ }^{58}$

Despite this, and the seeming impact on the strength of PTD, it is still important to explore it for

Series, vol 999, $171<$ https://www.refworld.org/docid/3ae6b3aa0 .html> accessed 13 February 2020.

50 M Turnipseed et al, 'Reinvigorating the Public Trust Doctrine: Expert Opinion on the Potential of a Public Trust Mandate in U.S. and International Environmental Law' (2020) 52 Environment: Science and Policy for Sustainable Development 10, 6-14.

51 See (n 33 - 36)

52 Komor v. USA CV-19-00293-TUC-RCC

53 Our Children's Trust, 'Landmark U.S. Federal Climate Lawsuit Our Children's Trust' <https://www.ourchildrenstrust.org/juliana-v -us> accessed 11 February 2020.

54 Cdn.ca9.uscourts.gov. (2020). [online] Available at: https://cdn.ca9.uscourts.gov/datastore/opinions/2020/01/17/18-36082.pdf [Accessed 14 Feb. 2020] at 29

55 Brown v. Board of Education, 347 U.S. 483 (1954).

56 ibid 63.

57 Climate Change Litigation, 'Urgenda Foundation v. State of the Netherlands - Climate Change Litigation' (Climate Chase Chart, $<$ http://climatecasechart.com/non-us-case/urgenda-foundation- $v$ -kingdom-of-the-netherlands/> accessed 19 January 2020.

58 (n 39). 
two reasons. Firstly, PTD is by its nature, exceptionally fluid, ${ }^{59}$ and thus it is very likely that the interpretation of it will change in the future, and thus it is important from a governance perspective to discuss PTD. Secondly, even if PTD could not be used to compel a government, it could potentially be used by a motivated trustee as justification for geoengineering action, once again raising governance issues. Even if such ideas are speculative, it is important to consider its possible interactions with geoengineering in advance of large-scale deployment becoming a distinct possibility. ${ }^{60}$

There is merit in exploring the relationship between PTD and geoengineering, despite the debateable strength of PTD - as even a weak principle would affect the governance of geoengineering. As governance is a key area of scholarly activity related to geoengineering, ${ }^{61}$ PTD is important to discuss. A comprehensive treatment of Atmospheric Trusts is offered by Wood, ${ }^{62}$ and of Public Trust Doctrine generally in environmental matters by Blumm and Guthrie. ${ }^{63}$ The approach has, however, not always met with success. ${ }^{64}$

Although a comprehensive taxonomy of the uses of the Public Trust Doctrine in environmental protection is beyond the scope of this article, it is worth acknowledging that there are several issues that must be addressed before the concept can be fully adapted to global governance structures. PTD's origins are believed to be Justinian, focusing on placing commu-

59 Matthew v Bay Head Improvement Association, 471 A.2d 355 (1984).

60 C2G, 'Governing Emerging Climate Technologies - C2G' (C2G, $<$ https://www.c2g2.net/governing-emerging-climate -technologies/>) accessed 11 February 2020.

61 C2G, 'Carnegie Climate Governance Initiative' (C2G, https://www.c2g2.net/ [Accessed 05 Feb. 2020].

62 M Woods, 'Atmospheric Trust Litigation Across the World' in C Sampford et al (eds.) Fiduciary Duty and the Atmospheric Trust (Taylor \& Francis Group, 2012).

63 M Blumm and R Guthrie, 'Internationalizing the Public Trust Doctrine: Natural Law and Constitutional and Statutory Approaches to Fulfilling the Saxion Vision' (2012) University of California Davis Law Review 44.

64 C Lewis, 'The Timid Approach of the Federal Courts to the Public Trust Doctrine: Justified Reluctance or Dereliction of Duty?' (1998) 19 Pub Land \& Resources L Rev 51

65 (n 30) 196

66 (n 39).

67 ibid 197

68 (n 40).

69 Alec L v. McCarthy USCA Case \#13-5192 Document \#1496137. nal resources in trust, (excluding private control) appointing trustees to preserve and make them available for specific purposes. ${ }^{65}$ Yet there appears to be some doubt how far this created positive duties of custodianship for the state. The Anglo-American common law tradition - which the Indian system, for example, draws upon ${ }^{66}$ - has evolved to create a PTD in which the focus is on the responsibility of the state to preserve the public trust for public use. ${ }^{67} \mathrm{PTD}$ thus prohibits conveyancing (which would transfer such assets to private hands), or the division of fiduciary responsibility by devolving the supervision of trustees onto inferior magistrates. Sax proposed a large expansion of the role PTD could play in environmental legislation, which is the origin of much of the modern interest in PTD.

Finally, it is important to address the entities to which PTD applies. Generally, PTD is considered to apply to the nation state ${ }^{68}$, although in a US context, PTD is a part of state law rather than federal law. ${ }^{69}$ It should be noted that there are no known cases of PTD applying to supranational entities.

\section{Discussion}

In order to evaluate the interaction between PTD and geoengineering, we consider the following questions.

- What is the relationship between geoengineering and assets currently held in trust?

- Can PTD be extended to the global commons, and if so, what is the implication for geoengineering?

- Is public trust doctrine strong enough to mandate geoengineering - either to protect existing trust assets, or the global commons?

\section{Protection of Existing Assets}

\section{a. Coastlines}

PTD is commonly enacted to protect coastlines. Coincidentally, coastlines are at particular risk from climate change. Accordingly, without negating the applicability of geoengineering to climate risks to other PTD assets, we find coastlines offer a useful example, which enables us to explore a range of relevant issues.

Most obviously, the risk to coastlines comes from sea level rise. The result of this will be (in the near 
term) potentially severe erosion; and (in the long term) submersion. Accordingly, the asset faces an existential threat - at least in its current form. Of course, new coastline must necessarily replace old, and thus there will be no net loss. Nevertheless, we regard such a laissez faire approach as fundamentally incorrect.

Firstly, in the Anglo-American tradition the application of PTD requires the protection of the asset presently in trust. It is not reasonable to assume that PTD allows the abandonment of present assets on the assumption that future assets will arrive to replace these - even if this process is inevitable.

Secondly, loss of existing coastlines does not necessarily result in equal replacement. When extrapolated to infinity, total submersion of land will result in total loss of coastline. For continental landmasses this argument is purely academic, as there is a limit to the inundation that could result from thermal expansion of the ocean, or from ice melt. However, in the case of small, low-lying islands, for example the Maldives, this loss will be total - thus resulting in unambiguous failure of the protection supposedly offered by the trust. As discussed, the right to life is included in the legal regimes of many small island states, and thus PTD could, in theory, be expanded to these jurisdictions through this. This total submergence would mean the governments were breaching both the PTD and the right to life. Here PTD would be the stronger of the two doctrines with regards to mandating geoengineering, as in theory relocation and other adaptation measures respect the right to life, whilst PTD forces the protection of existing assets. However, if the action taken to protect existing assets may threaten the right to life, as geoengineering may conceivably do, it is likely the more established principle of the right to life will take precedence.

This argument can be applied both to island states at risk from rising seas, and also to small islands owned by countries that are not themselves facing such an existential threat. This is because PTD forces the trustee to protect all the land held in trust - be it an entire state, or just a small island as part of a large state. This may be particularly relevant in the Indian context, where PTD is particularly well-established. An additional possibility is that, whilst coastline length may remain approximately constant, coastline value may drop substantially as a result of a creep inland. This may take the form of lost infra- structure (piers, etc.), as well as the intrinsic amenity value of particular beaches. For example, popular beaches may be lost, replaced by a coastline of bare rock. This value may be economic or aesthetic, as PTD can protect the inherent aesthetic value, ${ }^{70}$ thus making a large aesthetic loss a potential breach of PTD. This means that most destruction of coastline down to climate change could be considered a breach of PTD.

Thirdly, we regard a reasonable justification for public trust holdings of coastline to be more than protection of the asset for its immediate amenity value. Beyond the value of a beach for its direct services (e.g. recreation) there exists an indirect benefit as a bulwark against the ravages of the sea. A landowner adjacent to the beach experiences a value from the beach as a defence to his own land. It is partly on this basis that extensive programmes of coastal defence are enacted.

Geoengineering may protect coastlines in a variety of ways:

1. Preventing SLR, which would otherwise damage or inundate the coastline (as is).

2. Reducing storm intensity, which may cause erosion and physical damage.

3. Controlling ocean temperature, thus preventing harm to reefs particularly (which are themselves protective, particularly regarding wave damage).

4. Protecting species that rely on particular conditions of temperature or precipitation, to thrive in the coastal environment.

5. In the case of lime addition, controlling $\mathrm{pH}$ decrease from $\mathrm{CO}_{2}$ dissolution.

Accordingly, we find that application of PTD offers the opportunity for strong arguments in favour of geoengineering to be made, using the example of coastline management. These arguments differ somewhat for the arguments using PTD for mitigation and adaptation. Firstly, certain stretches of coastline have already been and will be severely affected or inundated due to warming from past emissions, meaning that, if states are to protect these stretches of coastline, they may be obligated to carry out geoengineering. This is particularly true on stretches of

$70 \mathrm{H}$ Babcock, 'Is Using the Public Trust Doctrine To Protect Public Parkland from Visual Pollution Justifiable Doctrinal Creep? Visual Pollution Justifiable Doctrinal Creep?' (2015) 42 Ecology L Q, $1-35$. 
coastline which are difficult to protect with adaptation. Similarly, the warming from past emissions has already intensified storms, meaning that, to carry out their fiduciary duty, trustees may again be obligated to carry out CDR. Furthermore, to achieve a limit of $1.5^{\circ} \mathrm{C}$ of warming, large-scale CDR deployment is necessary. As this $1.5^{\circ} \mathrm{C}$ target is necessary for the protection of many assets, CDR is therefore necessary for the protection of many assets. In these above cases, CDR may be too slow to protect many assets, thus justifying the use of SRM to protect these assets. Moreover, the prospect of a single state acting alone using full-scale SRM would be far more impactful on the local and global climate than by merely mitigating its own emissions or carrying out equivalent CDR. This means that the PTD may obligate the state to carry out SRM if other countries do not also mitigate. Finally, trustees may be seen as obligated to do all within their power to protect their assets, and this may include investigating CDR and SRM, alongside mitigation and adaptation measures.

\section{b. Navigable Waterways}

An alternative use of PTD is the protection and management of navigable waterways. Unlike with coastlines, the use of geoengineering confers a less obvious series of benefits. However, there are a range of problems that navigable waterways may face as a result of AGW:

1. Floods or droughts, which have direct effects on navigability, but also indirect effects such as silting.

2. Ecosystem changes, which may have impacts on navigability: e.g. propeller fouling from growth of vegetation.

3. More obliquely, it could be argued that maintenance of the economic case for navigation is part of the responsibilities of the trustees under PTD. For example, if a river were to serve as a transport corridor for croplands (which themselves were at risk from AGW), a case could potentially be made that navigation rights were affected.

We take the view that (3) above is tenuous at best, but we find generally that (1) and (2) are relevant con-

71 D Koweek, et al, 'Bubble Stripping as a Tool To Reduce High Dissolved CO2 in Coastal Marine Ecosystems' (2016) 50 Environmental Science \& Technology 7, 3790-3797. siderations. However, we note that a wholesale and systematic reduction of navigability is not understood to be an effect of AGW. Accordingly, we do not consider such navigability arguments as being central to PTD arguments. It is important to note that the use of SRM in particularly may in fact have a negative impact on navigability due to potential climate impacts. Rainfall reduction may conceivably result in lower river levels, for example.

\section{c. Fisheries}

Herein we use the word 'fisheries' loosely to cover all kinds of biological productivity from the sea. This may include shellfish, as well as seaweed. In all waterways and waterbodies managed under PTD (including coastal waters), there is a potential impact on fisheries from AGW. Marine species are sensitive to a range of impacts resulting from AGW. These may be direct sensitivity to temperature, or other direct sensitivities (notably to acidification). Furthermore, there is a significant chance of indirect effects - such as harm to fish species which are dependent on reef systems affected by AGW; or spawning grounds being disrupted by storms.

Accordingly, there is (in common with coastlines) a similar structure of arguments obligating protection of fisheries. We do not seek to repeat our above arguments, save to note that they may similarly serve to permit and/or obligate geoengineering.

One aspect of fisheries protection that is notable is not the legal or academic arguments surrounding PTD, but the advocacy of potential plaintiffs. Fisheries have significant economic value - and that value is concentrated in the hands of a relatively small number of people, who have a strong incentive to undertake lobbying or legal action in defence of their livelihoods. This means that early pleas for action for fisheries protection is to be expected. Consequently, pressure to use geoengineering in pursuit of such protection may come from this avenue, with PTD providing a potential mechanism.

\section{d. Reef Systems}

Reef systems deserve a special mention, as various forms of local protection exist - which are comparable to geoengineering, but likely fall short of a strict definition of the term. These include bubbling to remove $\mathrm{CO}_{2}{ }^{71}$ and shading using marine cloud bright- 
ening (MCB) ${ }^{72}$ These options would be open to countries that have threatened reef systems - e.g. Australia. ${ }^{73}$ Accordingly, these not-quite-geoengineering techniques may act as a bridge to a more general, global intervention in the climate. Even if a PTD case were to mandate geoengineering, taking global action to satisfy local plaintiffs would not sit favourably with all governments. Accordingly, the not-quite-geoengineering approach may be far easier a 'win' for plaintiffs to obtain, as a practical intervention.

These not-quite geoengineering approaches may be the only way to protect many reef systems, as the pre-existing warming already hugely threaten these systems $^{74,75}$. Here, PTD may mandate these approaches as the only way to save much of reefs, although there are no known cases that currently discuss PTD in relation to coral reefs. Moreover, many of the world's major coral reefs are in countries without a strong tradition of PTD, although feasibly such action could happen in an Indian context, for example. However, other natural features have been afforded legal personhood - such as New Zealand's Te Urewera park which may be a more fruitful route to protection than the comparable concept of PTD, as there is legal precedent for the success of this. ${ }^{76}$

\section{Extended Public Trust}

The question of whether public trust can be extended - e.g. to wildlife - is an important one to consider. Atmospheric trust litigation raises the question of whether the atmosphere can be considered in trust in the courts. Juliana vs USA failed, and may indicate that the extension of public trust to the atmosphere is inappropriate. However, Juliana is only in one legal regime, and on appeal may succeed, and therefore is not necessarily an indication that extension of PTD to the atmosphere is impossible. Moreover, the majority opinion does not indicate the government does not have a public trust obligation, merely that the federal courts cannot force the government to take action on that obligation. This would make it appear, therefore, that at this point the Federal Courts believe they cannot (or should not) force action upon a government. Outside of the USA, there are various indications that Atmospheric Trust Litigation may be more acceptable. For example, the Indian Supreme Court stated in that, amongst other natur- al resources, the public are beneficiaries of the 'airs ${ }^{177}$ and the state has a duty to protect these resources. However, there has thus far been no atmospheric trust litigation to test this.

Extending public trust to the oceans can be separated into a few questions: tidally influenced waters, regional waters (particularly where multiple jurisdictions are involved) and high seas. Tidally influenced waters have already been discussed. Regional waters may be brought into the discussion by the fact fisheries and other ocean resources are often held in public trust, and thus the ocean must be protected to protect these resources. ${ }^{78}$ High seas in particular present a difficulty in that they are under no national jurisdiction, and thus the extension of PTD to them would likely require a deferment to a supranational authority, most likely the UN. This will be very difficult for PTD to apply to, as it traditionally applies on a state level. However, the fact that resources, mostly fish, move from a state's jurisdiction to the high seas complicates the states duty to protect these resources; it is unclear whether the state is only obliged to protect resources under their own jurisdiction, or to protect resources at all times if they may come under their jurisdiction. Due to the many legal problems of the latter scenario, it appears to the authors the former scenario is more appropriate.

Finally, there is the separate question of whether wildlife can be considered to be protected under public trust. Firstly, it is clear that fisheries are clearly protected under public trust. However, courts, particularly in the USA, have consistently declined to expand the PTD to inland wildlife, ${ }^{79}$ and thus at this point, would appear difficult to extend PTD to

72 J Latham et al, 'Can Marine Cloud Brightening Reduce Coral Bleaching?' (2013) 14 Atmospheric Science Letters 4, 214-219.

73 D Normile, 'Survey Confirms Worst-ever Coral Bleaching at Great Barrier Reef' (Science Mag, <https://www.sciencemag.org/news/ 2016/04/survey-confirms-worst-ever-coral-bleaching-great-barrier -reef>) accessed 2 February 2020

74 ibid

75 Secore International, 'Why Corals Need our Help' (Secore International, <http://www.secore.org/site/corals/detail/coral-reefs -are-dying.23.html>) accessed 2 February 2020.

76 ibid

77 (n 40).

78 K Fletcher, 'Regional Ocean Governance: The Role of the Public Trust Doctrine' (2006) 16 Duke Environmental Law \& Policy Forum 2, 187-204.

79 J Huffmann, 'The Limits of the Public Trust Doctrine' (PERC, $<$ https://www.perc.org/2019/06/19/the-limits-of-the-public-trust -doctrine/>) accessed 7 February 2020. 
wildlife in general in the American tradition. However, in India, PTD is extended to 'forests and ecologically fragile areas', ${ }^{80}$ indicating that wildlife may be able to be considered under PTD there. Moreover, due to the changeable nature of PTD, and the fact it exists in multiple legal jurisdictions, there may in the future be scope for this extension to occur, if there is enough statutory grounding. ${ }^{81}$

Much uncertainty remains, regarding whether public trust can be extended. However, it must be noted how changeable a principle the public trust doctrine is, and thus how powerful a tool it could potentially be. In the words of the New Jersey Supreme Court ' $[\mathrm{We}]$ perceive the public trust doctrine not to be "fixed or static," but one to "be molded and extended to meet changing conditions and needs of the public it was created to benefit." ${ }^{22}$ Thus, despite the uncertainty as to whether PTD can be extended, it is important to speculate on the implications if it could be, as the PTD may be moulded and extended to include global commons in the future.

The fact that PTD is not part of many legal regimes, and is not explicitly part of international law, would make it harder to make PTD the basis for global geoengineering action. Given doctrines of sovereign immunity, it would be difficult to imagine how citizens of a given state with PTD traditions could compel other states to adopt such doctrines; this is currently a matter for diplomats, not for courts. ${ }^{83}$ Paradoxically, therefore, the protection of more minor assets (e.g. coastlines) may end up being a more fruitful avenue for PTD actions than the global commons.

80 (n 40).

81 (n 36).

82 Matthew v. Bay Head Improvement Association, 471 A.2d 355 (1984).

83 P Dalton, 'Sovereign Immunity: The Right of the State Department and the Duty of the Court' (1965) Wm \& Mary L Rev 6, 70.

84 J Rogelj et al, 'Mitigation Pathways Compatible with $1.5^{\circ} \mathrm{C}$ in the Context of Sustainable Development' in Masson-Delmotte, et al. (eds.) Global Warming of $1.5^{\circ} \mathrm{C}$ (IPCC, 2018).

85 T Lenton et al, Tipping Elements in the Earth's Climate System ' (2008) 105 Proceedings of the National Academy of Sciences 6 , 1786-1793.

86 E.g. the United Nations Convention on the Law of the Sea (1982).

87 J Latham et al, 'Weakening of Hurricanes via Marine Cloud Brightening' (2012) 13 Atmospheric Science Letters 4, 231-237.

88 (n 8).

89 P Lefale and C Anderson, 'Climate Engineering and Small Island States: Panacea or Catastrophe?' in J Blackstock and S Low (eds.) Geoengineering our Climate? Ethics, Politics, and Governance (Taylor \& Francis, 2018).
Even if courts do not mandate specific climate policies, which the precedent Juliana $v$. USA suggests, and instead mandate generalised climate action or action on atmospheric pollution, CDR may be the only appropriate approach alongside mitigation to remedy pollution. SRM only remedies warming, not pollution, thus the government may still be obligated to carry out CDR. Indeed, every IPCC mitigation scenario required some amount of CDR. ${ }^{84}$ If climate tipping points are reached, feedbacks mean that increased emissions may occur even with mitigation, ${ }^{85}$ making CDR necessary to protect the atmosphere. Governments may therefore be obligated to carry out CDR - whether the courts mandate it specifically, or instead specify climate action in general. The fact that international law ${ }^{86}$ may already restrict or prohibit ocean fertilisation (due to it being considered pollution) means that carrying out such activities may be seen as a breach of PTD, too.

\section{Applicable Actors}

The nature of geoengineering is such that the effects of an intervention necessarily tend to be global, notwithstanding the potential use of some techniques to achieve local scale effects, as previously discussed. ${ }^{87}$ We note also the low cost of potential interventions, placing SRM geoengineering within reach of many actors. ${ }^{88}$ Accordingly, it is conceivable that a scenario may arise where PTD is used as a legal framing for an intervention where, by necessity, the acting party is responsible for a very small minority of assets influenced. A popular framing in the literature is that of a small island state facing inundation. ${ }^{89}$ Notwithstanding the relative political impotence of such states, this framing is nevertheless instructive, as it highlights the imbalance of intent and effect fundamental to geoengineering deployments.

By contrast, it may be greatly easier for a geographically larger nation (US, Russia, Australia) to undertake geoengineering based on a PTD mandate. The Russian coastline is, for example, a significant proportion of the global coastline. Accordingly, a case for intervention would prima facie be seen as more typical and representative than would global intervention to protect the coastline of a very small nation.

Similar concerns may exist at state level. Consider, for example, Massachusetts - a state with a significant population and many historical assets in low- 
lying coastal areas. A PTD case in this state, seemingly mandating geoengineering, would assumedly have less political weight than would an equivalent Federal intervention. It should be noted in a US context, where PTD has a lot of traction and the majority of geoengineering research-based cases have been filed ${ }^{90}$ PTD seemingly only applies on a state level, ${ }^{91}$ and Juliana v. USA appears to have failed on a Federal Level. ${ }^{92}$ This makes it potentially politically difficult to mandate SRM based on PTD in the American context.. It is unlikely, in nakedly political terms, that a large and powerful country (e.g. China) would endure a single US state undertaking geoengineering without the overt or assumed consent of the Federal government. Nevertheless, such action could reasonably be fronted by sub-national actors.

\section{Intervention Types}

We note that existing PTD cases make specific reference to levels of carbon dioxide below present-day levels. ${ }^{93}$ Accordingly, an assumption of a requirement for CDR is (to an extent) 'baked in' to such an action. Indeed, the deployment of CDR (as so-called 'Negative Emissions Technologies') underpins recent climate agreements - indicating a current global level of acceptability. ${ }^{94}$ It could even be argued that such commitments act to place the atmosphere in a form of de facto public trust. As stated, there are cases that argue for the placing of the atmosphere in public trust, particularly with regards to carbon dioxide levels, which potentially mandates both mitigation and $\mathrm{CDR}$, with mitigation to stop $\mathrm{CO}_{2}$ levels increasing in the future, and CDR to reduce levels back to what is considered an 'acceptable' state. However, if these two were viewed as the same, that may create a potential moral or morale hazard issue ${ }^{95}$ - which is beyond the scope of this article - and something that PTD appears to have no inherent mechanism against. Accordingly, we suggest that a reaction to a successful establishment of a public trust obligation will conceivably include such obligations upon the state so bound. This is potentially more globally significant for a large state (e.g. the US) than it is for a small one (e.g. Tuvalu), which may practically lack the means to act. However, this depends on interpretation. Taking the above states as examples, it may conceivably fall upon Tuvalu to use CDR to reverse its own historic emissions. This is a challenging task economi- cally ${ }^{96}$ but not one that is likely to test geophysical constrains globally, due to the small total emissions of such small states. However, if the intervention demanded under a PTD action was for Tuvalu alone to effect the necessary changes to global atmospheric composition, this would be patently unachievable. There is no conceivable way that the economy of Tuvalu would be able to sustain such a feat.

An alternative pattern of intervention is SRM. SRM is imperfect; it does not address comprehensively the issue of ocean acidification or atmospheric $\mathrm{CO}_{2}$ levels, which would be particularly relevant if PTD were extended to the oceans or atmosphere in general - but it nevertheless offers an option for minor economies to have a global impact. It is likely that a legal argument can be made that, in the absence of capacity for effective CDR, the defendant (i.e. the state) would be obligated to undertake SRM, this being the most viable way to discharge properly its duties to protect the asset in question. SRM would cost far less for a much larger impact on the climate than CDR, and therefore may be considered more effective. Such a state of affairs would obviously present a major political challenge to a smaller, less powerful state - SRM being inherently more controversial, due to its artificial (as opposed to restorative) nature. In a situation where an obligation to geoengineer was in place, navigating the resulting pressure - conceivably including sanctions and military threats - may pose major political challenges for smaller states especially. Considering the precedent Juliana vs USA may set for the extent to which PTD can mandate specific policies, the authors deem it unlikely that PTD would be able to obligate a government to undertake such controversial policies. As we have suggested earlier, we regard the commonality

90 E Necheles, 'Funding for Solar Geoengineering Research from 2008-2018'<https://geoengineering.environment.harvard.edu/ files/sgrp/files/sg_funding_chart_0.pdf $>$ accessed 7 February 2020.

91 Alec L vs McCarthy USCA Case \#13-5192 Document \#1496137

92 (n 50)

93 ibid

94 UNFCCC Secretariat, 'Paris Agreement, FCCC/CP/2015/L.9/Rev.1'.

95 A Lockley, and D Coffman, 'Distinguishing Morale Hazard from Moral Hazard in Geoengineering' (2016) 18 Environmental Law Review 3, 194-204.

96 World Resources Institute, 'CAIT - Historical Emissions Data (Countries, U.S. States, UNFCCC)' (WRI, <http://www.wri.org/ resources/data-sets/cait-historical-emissions-data-countries-us -states-unfccc> accessed 22 May 2016. 
of such obligations (i.e. because many countries have assets, and a mandate to protect them, in common alignment), that there exists a naturally transnational collective approach to deployment. Accordingly, we suggest that an isolationist consideration of geoengineering under PTD simply does not form a practical framing for consideration, yet it may act as a legal fig leaf to provide cover for the actions of a state already determined to geoengineer.

Moreover, in some legal regimes, PTD is based on the right to a safe environment. ${ }^{97}$ Given the potentially negative environmental impacts of certain SRM measures ${ }^{98}$, it may be effectively argued that it is not a fulfilment of the obligations of PTD. However, if SRM had an overall positive impact on the safety of the environment, which in any extreme warming scenario it likely would, this argument may sway courts. It should be noted that, in theory, PTD could be used to mandate some form of geoengineering to remediate global warming, yet not mandate mitigation of carbon emissions. PTD only requires the protection of a natural resources as long as it is considered in the public interest to protect that resource. ${ }^{99}$ Due to anticipated economic costs of mitigation ${ }^{100}$, a court could conceivably consider it in the public interest not to mitigate, particularly if the cheaper 'solution' of SRM was available. ${ }^{101}$ Additionally, particularly with low-emissions states, any local mitigation would be incomplete or even trivial - as domestic courts could not ordinarily bind foreign governments. Such a scenario would result in snowballing dangers, from indefinitely increasing SRM absent mitigation. ${ }^{102}$ To avoid the threat of such a situation occurring, a transboundary governance system may be established, although the authors deem this unlikely unless there is a significant strengthening and extension to the commons of PTD.

\footnotetext{
97 (n 44)

98 A Nalam et al, 'Effects of Arctic Geoengineering on Precipitation in the Tropical Monsoon Regions' (2017) 50 Climate Dynamics 9-10, p 3375-3395.

99 (n 40).

100 IPCC, 'Climate Change 2014: Synthesis Report. Contribution of Working Groups I, II and III to the Fifth Assessment Report of the Intergovernmental Panel on Climate Change' (2014) 151.

101 (n 9).

102 A Jones et al, 'The Impact of Abrupt Suspension of Solar Radiation Management (termination effect) in Experiment G2 of the Geoengineering Model Intercomparison Project (GeoMIP)' (2013) 118 Journal of Geophysical Research: Atmospheres 17, 9743-9752.
}

\section{Strength of PTD}

The discussion thus far has focus on whether PTD could potentially mandate geoengineering, in relation to assets currently held in trust, and consideration of an extension to the global commons. However, whilst an idealised version of PTD may be strong enough to mandate this, it is important to discuss the strength of the doctrine as that profoundly impacts its legal potential.

The majority opinion in Juliana vs USA seems to suggest that the courts do not have the power to provide the plaintiffs with their relief, i.e. that such generalised relief is beyond the court's power. Not only would the implications of this be that in a US Federal context the courts could not compel the government to act, based on PTD - but also that they could not mandate them to act based on any other legal principle, in such a generalised sense. The court also was sceptical that the relief requested would actually have a substantial enough global impact to be warranted. An implementation of SRM would certainly have this effect but, due to the policy complexities, it is very likely the court would rule it beyond their power.

The minority opinion did rule the Article III court had the power to compel the Federal Government to act. However, this was not based on PTD. Whilst this does show that in the future geoengineering action may well be mandated by courts, it also indicates that - when compared to other legal principles that may be invoked - PTD is comparably weak. It is therefore very unlikely for PTD to mandate any climate action in a US Federal Court.

However, PTD is not a uniquely American principle, and thus, in other jurisdictions, particularly India, PTD may be used to mandate action. It must be noted that India does utilise US precedent with regards to PTD. However, as these are not the same jurisdictions, and there are constitutional differences, there still remains a small possibility of PTD being invoked in India to mandate geoengineering. There are other countries PTD also may apply in, although in India, the principle is the most developed. Even so, as far as the authors are aware, there are no examples of PTD being successfully used to mandate any form of climate action in any jurisdiction thus far.

It is not necessary for a discussion of the relevance of geoengineering to PTD to resolve all the outstand- 
ing issues of PTD. Practical use of PTD in geoengineering advocacy may catalyse diplomatic efforts towards a multi-state, multi-lateral deployment, and thus involve some abrogation of national sovereignty to a supranational authority: this may be regional (such as the European Union) or global (such as the United Nations). In the scenarios considered above, there are opportunities for national, multinational and global solutions, but the legal issues around PTD differ in each case. The alternative interpretation, in which a state would consider only its own beaches (whilst geoengineering the whole planet) is clearly an impractical proposition - although it may serve as a fig-leaf, to provide legal cover for a state already set upon geoengineering.

When compared with other principles, such as the right to life or the right to a safe environment, PTD is comparably weak - both in law and in the public consciousness - and this limits the likelihood that it will play a major role. Moreover, given the recent case in the UK based on the Paris Agreement, ${ }^{103}$ it seems further unlikely that PTD will be an attractive and necessary way of pursuing climate action. However, it must be noted that the Paris Agreement could not be used to mandate SRM, due to it not fulfilling the requirements of Article $4 .{ }^{104}$

\section{Conclusions}

In conclusion, we find that public trust doctrine can be applied instructively when evaluating geoengineering. Assuming an effective PTD, without the constraints of its weakness, the authors find a range of clear arguments for deploying geoengineering as an instrument of existing PTD obligations, particularly regionally, where less of a clash exists with other legal principles. These not-quite-geoengineering approaches seem to be most compatible with the currently-weak status of PTD.

PTD as a principle is probably more likely to compel government to act on climate change in general, rather than to take any specific approach. This article has set out the ways in which geoengineering may allow a government to fulfil its role as a trustee, alongside adaptation or mitigation measures. However, we do note that it would be conceivable, if speculative, for geoengineering alone to be taken to fulfilling a government's duty. This is particularly the case where a small or impoverished state may otherwise be powerless to act. However, such action (or potential action) may result in mitigation deterrence.

We find geoengineering may allow a government to carry out its PTD obligation by protecting assets in public trust (specifically the shoreline) and may also be practically effective in defending other assets held in public trust. We also find these obligations unique when compared to mitigation. Unlike mitigation, CDR can address historic emissions, and SRM the warming from historic emissions. Hence, our arguments in this regard apply to both SRM and CDR. However, we note that the slower-acting and costly nature of CDR means that it does not necessarily constitute an immediate alternative, particularly to a state the lacks the economic capacity to undertake globally-significant CDR. Additionally, regional forms of not-quite-geoengineering may be similarly mandate, as the only way to protect certain assets under threat from current temperature rise.

PTD may also mandate mitigation, to prevent future harm. As climate change from historic emissions already threatens many areas held in public trust, geoengineering may become the only way to protect these assets (if adaptation is not feasible). Moreover, $\mathrm{CDR}$, is the only way to remedy residual $\mathrm{CO}_{2}$, further making the obligation to carry it out unique from mitigation. Furthermore, as CDR has been deemed necessary, on top of mitigation, for fulfilling the Paris Agreement and limiting temperature rise above dangerous levels, the obligation to carry it out could not be substituted for mitigation. Thus, although PTD may be used to urge action on climate change in general, geoengineering may be the most appropriate, or at least an appropriate, course of action in many cases - particularly with regards to specific assets, i.e. those threatened principally by historic emissions, and out of scope for practical adaptation. Moreover, the trustees are obligated to do all they can do to protect the assets, indicating that geoengineering may effectively be mandated on top of mitigation and adaptation - particularly if such an approach would be affordable, where others are not. The fact geoengineering may be mandated does not preclude a mandate to carry out mitigation and adaptation as well. This may particularly be the case in the example of

103 R (Heathrow Hub Ltd) v. Secretary of State for Transport [2020] EWCA Civ 213.

104 Paris Agreement, Art 4. 
larger and more polluting states, whose emissions are more generally significant in the risk to trust assets.

Alternatively, the extension of PTD to the global commons may block certain geoengineering actions (such as ocean iron fertilisation, or potentially stratospheric aerosol injection) if PTD compels the protection of assets from pollution - which OIF and SAI may be considered to be.

We find that geoengineering generally (and SRM specifically) may offer a useful intervention for assets under public trust in the short to medium term. Additionally, we note that PTD poses a strange paradox of action: whilst the nature of PTD creates an inherently atomised framework of responsibility where each state is separately obligated - there nevertheless exists a camaraderie of obligation. Many states may ultimately share the fact that they have assets under PTD that are threatened by AGW - and they also share a common solution. The paradox is thus that superficially atomised state responsibility may in fact be a unifying factor - a common banner under which geoengineering is triggered.

We observe that a second paradox exists - where it may be easier to compel geoengineering to protect a single beach than to protect the entire atmosphere. This paradox may make it harder to compel action based on PTD, but also may help catalyse the establishment of transboundary governance frameworks.

We note the way PTD interacts with other legal principles, both nationally and internationally, is far from obvious and settled ${ }^{105}$, and may reduce the capacity for a state to carry out geoengineering - even if PTD mandated it or could mandate it under the general notion of climate action.

As international law seems to be more restrictive of SRM (and certain CDR approaches, like OIF), it would appear more likely that a PTD obligation would cause a state to consider CDR, which is less likely to be prohibited by other laws. Nevertheless, the fact that SRM is faster and cheaper than CDR

\footnotetext{
105 R Frank, 'The Public Trust Doctrine: Assessing Its Recent Past \& Charting Its Future'(2012) $45 \cup$ C Davis L Rev 665, 677.

106 N.B. The effect of SRM on the carbon cycle.
}

may result in it being preferred - or, for less powerful states, being the only viable option to control temperature. It is far from obvious which way the courts would go on such a ruling - or which way policy would go if, as we deem more likely, climate action in general were mandated. In a case where PTD action specifically concerned carbon dioxide levels in the atmosphere, SRM could not be mandated. ${ }^{106}$ All of this assumes an idealized scenario where PTD can be used to mandate any form of climate action.

However, we note PTD's weakness when compared to other legal principles, and therefore its limited potential for usage. Despite many environmental activists' enthusiasm for PTD, there is very little evidence of its successful usage in climate change litigation, at least in the jurisdictions in which it has been tried. Similarly, as climate change has become more grave, other principles - such as the right to life - look to be stronger alternatives to PTD. These alternative principles may instructively be applied to geoengineering, and thus are likely to be more fruitful avenues for legal action on geoengineering. We also find it is presently unlikely PTD will be used to mandate geoengineering in a US Federal context, although there is a possibility that it may be more successful in another jurisdiction, such as India.

The authors recognise current activist interest in PTD. Due to the fluid nature of PTD, future action may strengthen its legal status; in which case, the way PTD relates to geoengineering will become highly relevant. The authors find that, in the present legal situation, it is very unlikely that courts will mandate geoengineering based on PTD. For this to happen, PTD would have to be significantly strengthened.

Finally, we note that this article cannot be a complete analysis of all conceptions of PTD in all jurisdictions, with respect to their relationship to geoengineering. Rather, it is a general study into the relationship of geoengineering and PTD in the countries in which PTD is most established, chiefly India and North America. Moreover, it is important to recognise how changeable the application PTD is, and thus what is true of a particular legal regime at the moment may soon vary. 